Title no. $79-11$

\title{
Mortar Constituent of Concrete in Compression
}

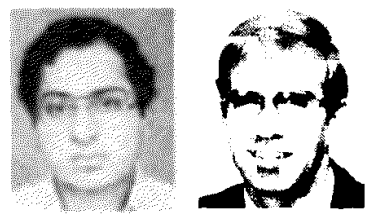

by Ataullah Maher and David Darwin

A study of the behavior of the mortar constituent of concrete under monotonic and cyclic uniaxial compression is summarized. Two mixes were used, with proportions corresponding to concretes with water-cement ratios of 0.5 and 0.6 . Forty-four groups of three specimens each were tested at ages ranging from 5 to 70 days. Complete monotonic and cyclic envelopes were obtained using six different loading regimes, including cycles to specified strains. Major emphasis was placed on tests using relatively high stress cycles. Accumulation of residual strain and changes in the initial modulus of elasticity were used to evaluate damage and structural change. The maximum strain appears to be the major factor controlling damage in mortar, but the total cyclic strain range and/or the number of load cycles also play significant roles. The behavior of concrete and mortar is highly similar, indicating that the mortar constituent may control the primary stress-strain behavior of concrete.

Keywords: compression; compressive strength; concretes; cyclic loads; damage; modulus of elasticity; mortars (material); strains; stresses; stress-strain relationships.

Recent studies ${ }^{16}$ have demonstrated that the nonlinearity of concrete under compressive loading is highly dependent on the nonlinearity of its cement paste and mortar constituents. Cement paste and mortar are not elastic, brittle materials as supposed in the past, ${ }^{7}$ but are nonlinear materials that are damaged continuously under load. ${ }^{3,8}$ The process of damage in concrete is also continuous and begins at very low strains. ${ }^{2.4}$ These recent studies seem to diminish microcracking as the most important factor in the nonlinear behavior of concrete, ${ }^{9}$ and strongly indicate the need for further study of both the relationships between the behavior of concrete and its constituents and the factors that control the behavior of concrete under general types of loading.

The present study evaluates the characteristics of the mortar constituent of concrete under monotonic and cyclic compression. Complete details of the study are presented in Reference 10.

\section{EXPERIMENTAL WORK}

During the experimental phase of this research, the behavior of the mortar constituent of concrete under monotonic and cyclic uniaxial compression was studied. Specimens were loaded using a closed-loop, electrohydraulic testing machine. Complete stress-strain curves for monotonic compressive loading were obtained. To determine the degree of softening and loss of strength produced by cyclic loading, a number of loading regimes were investigated. The tests closely paralleled those performed by Karsan and Jirsa ${ }^{11}$ in their study of concrete.

\section{Materials}

Materials used were:

Type 1 portland cement.

Fine aggregate: Mainly quartz, with 10 to 15 percent chert, larger particles contain some limestone and dolomite. Fineness modulus $=2.9$. Bulk specific gravity (saturated surface dry) $=2.62$. Absorption $=0.5$ percent. Source: Kansas River, Lawrence, Kan. The sand was passed through a $4.75 \mathrm{~mm}$ sieve and washed before use.

Coarse aggregate: $1 / 2$ in. $13 \mathrm{~mm}$ nominal size, crushed limestone. Bulk specific gravity (saturated surface dry) $=2.52$. Absorption $=3.5$ percent. Unit weight $=90$ $\mathrm{lb} / \mathrm{ft}^{3}\left(1440 \mathrm{~kg} / \mathrm{m}^{3}\right)$. Source: Quarry, Perry, Kan. Used in prototype concrete.

Two mixes of mortar were used, corresponding to concretes with water-cement ratios of 0.5 and 0.6 . The mix proportions of the concretes and the constituent mortars are given in Table 1.

\section{Preparation}

Test specimens (Fig. 1) were 14 in. (356 mm) high with flared ends. The middle 6-in. (152-mm) portion of the specimens was prismatic and had a uniform, 2 -in. $(51 \mathrm{~mm}) \mathrm{sq}$ cross section. Specimens were placed vertically in metal forms. The mortar was consolidated in three layers, each layer rodded 25 times with a $3 / 8$ in. $(9.5-\mathrm{mm})$ rod. The forms were then sealed at the top and the specimens stored in a horizontal position to reduce the effects of bleeding.

\footnotetext{
Received July 28, 1981 , and reviewed under Institute publication policies Copyright (C) 1982, American Concrete Institute. All rights reserved, including the making of copies unless permission is obtained from the copyright proprietors. Pertinent discussion will be published in the January-February 1983 ACI JoUrnal if received by Oct. 1,1982 . 002-8061/82/02 0100-10 $\$ 2.50$.
} 
Afaullah Maher received his BE from the University of Karachi and his MSCE and PhD from the University of Kansas. He is currently principal research officer with the Council for Works and Housing Research, Ministry of Science and Technology, Pakistan.

David Darwin, FACl, is an associate professor of civil engineering at the University of Kansas. He is an active researcher in the fields of plain and reinforced concrete, chairman of $\mathrm{ACl}$ Committee 224, Cracking, a member of ACI-ASCE Committee 445, Shear and Torsion, and past president of the ACJ Kansas Chapter.

After $24 \mathrm{hr}$, the specimens were removed from the molds and stored in the curing room under standard conditions.

Specimens to be strain-gaged were taken out of the curing room 3 days before the test. The rest of the specimens were taken out approximately $2 \mathrm{hr}$ before the test. All specimens were ground immediately after removal from the curing room to obtain a uniform cross section.

Preparation and testing required 3 to $8 \mathrm{hr}$, depending on the type of the test. The specimens were allowed to dry during this period. Specimens were tested at ages ranging from 5 to 70 days.

\section{Testing}

Specimens were seated in the testing machine using a $1 / 8$-in. (3-mm) layer of high strength gypsum cement. The strength of the gypsum cement was in excess of $7000 \mathrm{psi}(48 \mathrm{MPa})$ at the time of test.

A $50,000 \mathrm{lb}(222 \mathrm{kN})$ capacity closed loop, electrohydraulic testing machine was used. The load was transmitted through flat rigid platens.

To obtain complete records of the descending portion of the stress-strain curve, a constant strain rate (strain-control-ramp) was used throughout each test. For cyclic loading, the load limit detectors of the testing machine were modified to allow a reversal in the direction of load at the specified maximum and minimum stress limits, while using the strain-control-ramp. When the load failed to reach the upper load limit during the loading portion of a cycle, the system continued to increase the strain at the specified rate, and a complete record of the remaining portion of the descending branch of the stress-strain curve was obtained.

A variable gage length compressometer was used to measure the axial strain [Fig. 2(a)]. The compressometer was attached to wood strips on the test specimens using setscrews. A 3 in. (76 mm) gage length was used for all tests. A strain gage-type extensometer was installed on the compressometer to monitor the strain and provide closed-loop control for the testing machine.

\section{Test program}

Forty-four batches of three specimens each were tested. The specimens were subjected to various loading regimes within batches. A key to specimen identification is presented in the appendix. Six different load regimes were used: monotonic loading, cyclic loading to the envelope, cyclic loading with a constant strain increment between successive cycles, cyclic loading between fixed maximum and minimum stresses, cyclic
Table $1-$ Mix proportions

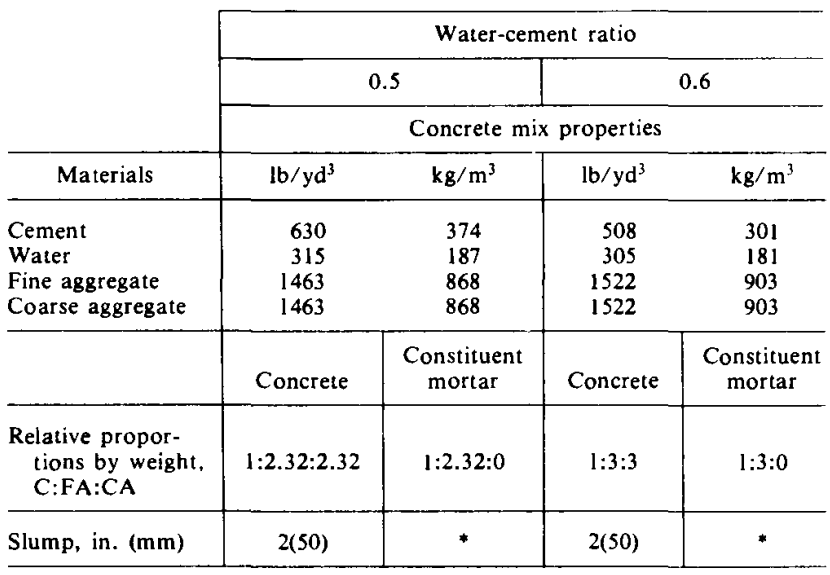

*Too fluid to measure.

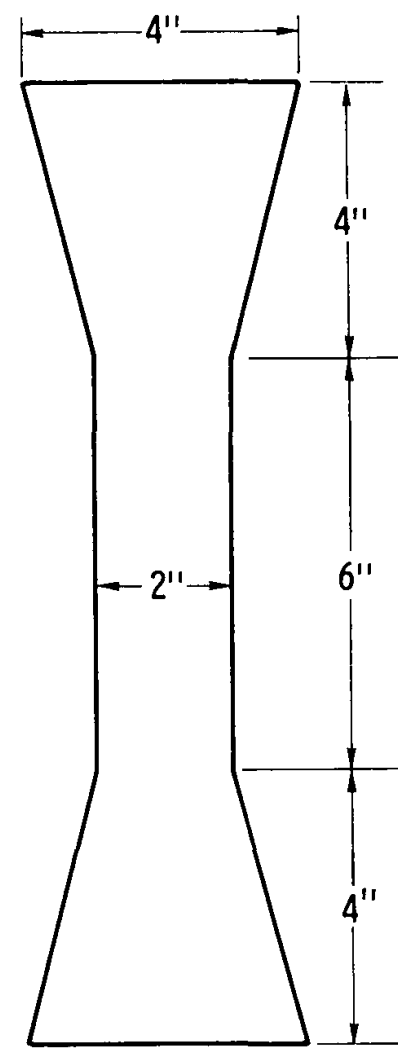

(a) Front View

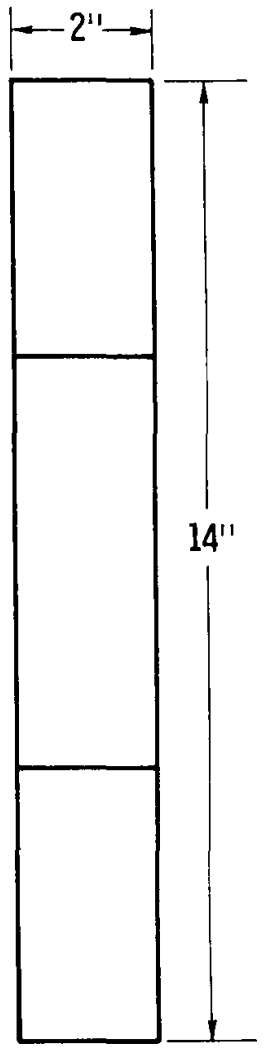

(b) Side View
Fig. 1 - Test specimen $(1 \mathrm{in} .=25.4 \mathrm{~mm})$

loading to specified strains, and cyclic loading to common points.

\section{Monotonic loading}

\section{RESULTS}

This group of tests was designed to study the monotonic stress-strain behavior, investigate the existence of an envelope curve, and provide data to compare the behavior of mortar under monotonic and cyclic loading. 


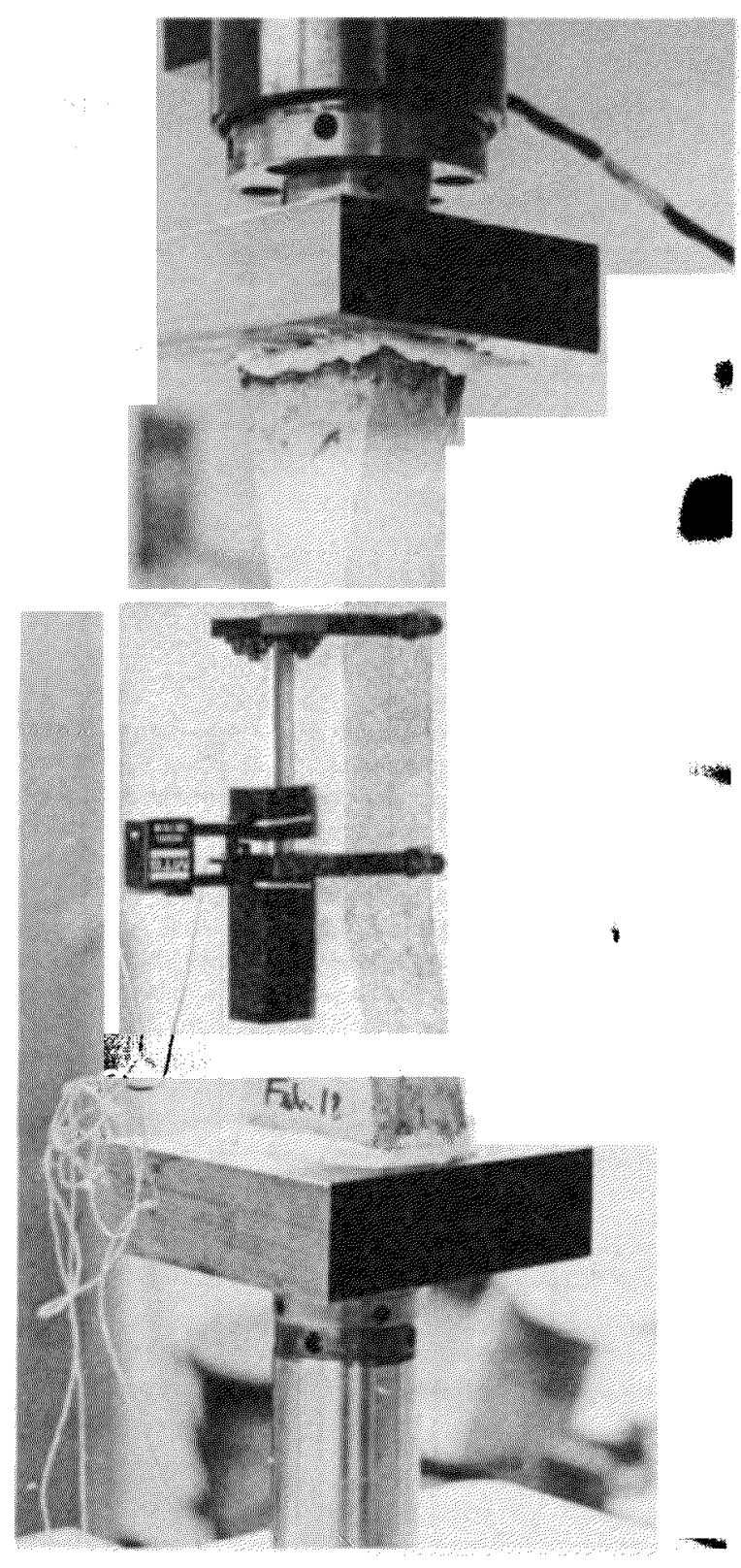

Fig. 2 - Test specimens failure

Fig. 3 shows a typical stress-strain curve. As the load increases, the material softens. Hairline cracks begin to appear in the specimen shortly after crossing the peak of the stress-strain curve. As the strain increases further, the size and length of these cracks increase [Fig. 2(b)], accompanied by a large increase in the lateral strain. At larger strains, sliding of the material in the cracked zone is observed. This sliding appears to be the major component of both the longitudinal and the lateral strain in the descending branch of the stressstrain curve.

Fig. 4 illustrates the change in Poisson's ratio for the test illustrated in Fig. 3. Both the total and the incremental Poisson's ratios increase continuously with increasing longitudinal strain, indicating that the damage process is continuous. There appears to be no special significance to the strain associated with the peak stress

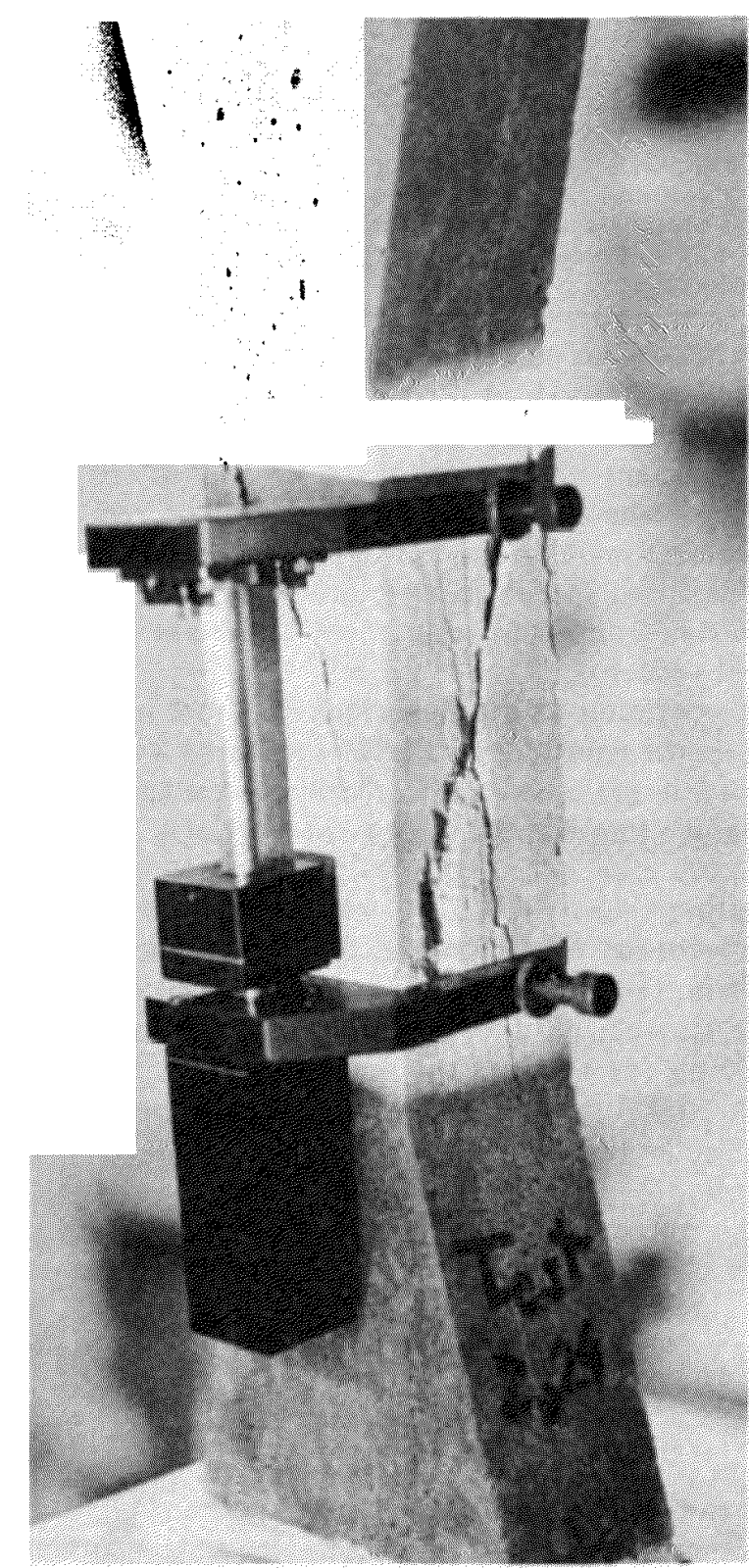

(a) Before testing (b) After

(0.0027). The large increase in the total Poisson's ratio (at about 0.004) corresponds with the appearance of macroscopic cracks within the prismatic portion of the specimen.

A comparison of the tests ${ }^{10}$ indicates that for the same mix proportions, age, and rate of loading, the stress-strain curves show the most scatter in the descending branch. The initial modulus of elasticity and the strain corresponding to the peak stress increase with increasing strength, whether a function of age or water-cement ratio. The descending branch of the stress-strain curve becomes steeper with increasing strength.

For monotonic loading, the peak stress was reached between 7 and $15 \mathrm{~min}$. For cyclic loading, the peak stress was reached between $1 / 2$ to $2 \mathrm{hr}$. To study the effect of this time difference on the stress-strain be- 


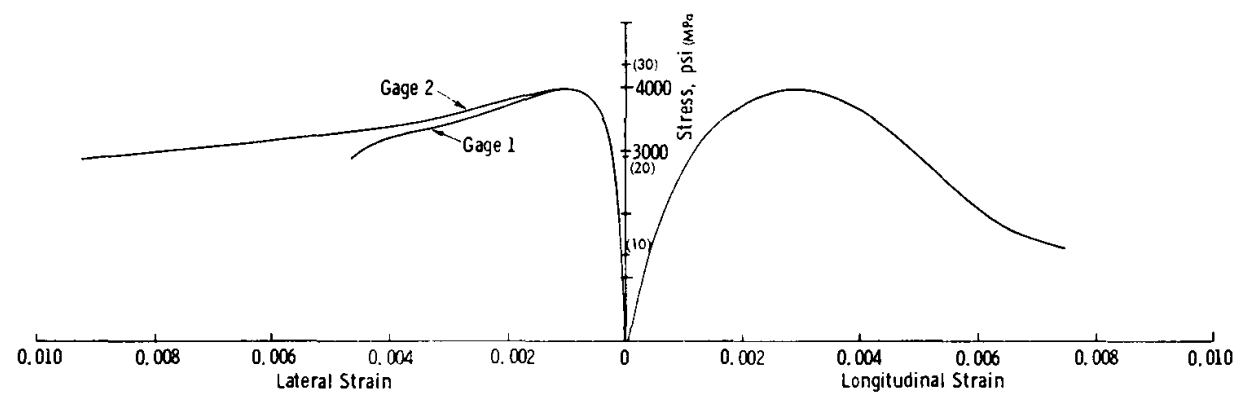

Fig. 3 - Stress-strain curves for monotonically loaded Specimen 19-1/M/29/0.6

havior, monotonic loading tests were conducted in which the time needed to reach the peak stress was approximately $1 \mathrm{hr}$. The specimens loaded at the slower rate tended to have a lower strength, a higher strain corresponding to the peak stress, and a higher descending branch of the envelope curve. This corresponds to similar observations for concrete. ${ }^{2}$

\section{Cyclic loading}

The basic characteristics of mortar under cyclic compression are illustrated in Fig. 5. When the material is unloaded, an additional permanent or residual strain is accumulated. Upon reloading, the stress-strain curve passes below the point at which it was previously unloaded (the point of intersection of the unloading and loading curves is called a "common point")." The initial modulus of elasticity of each successive loading cycle is less than that of the previous cycle. A smooth curve passing through the upper portions of the cycles represents the "envelope curve." To reach the same value of stress on reloading, the material undergoes a larger value of strain. Both the loading and unloading components of a cycle are nonlinear.

Past the peak of the envelope, the cyclic specimens

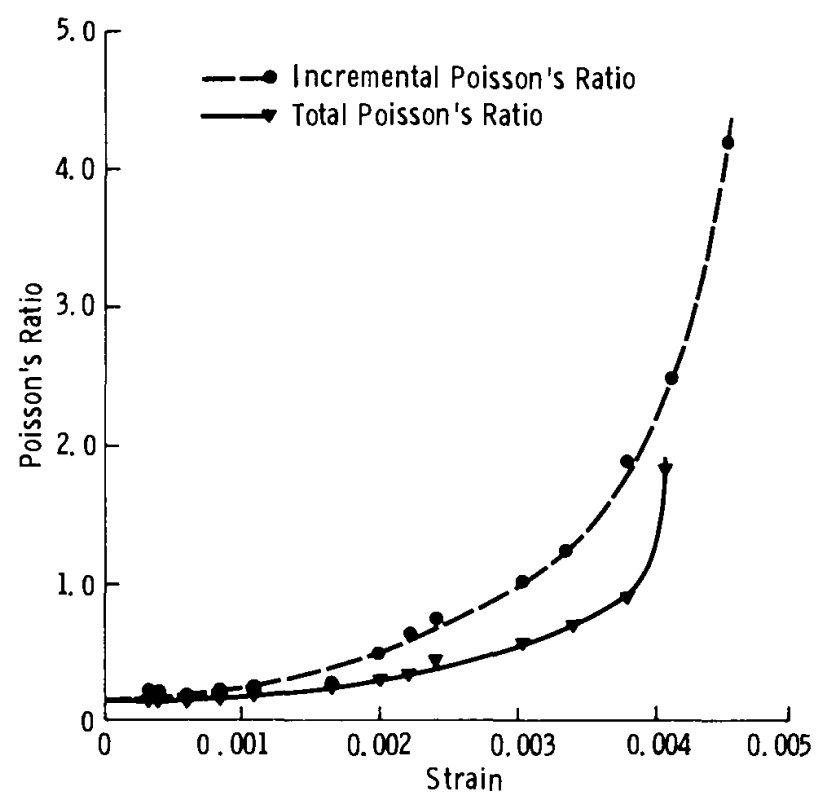

Fig. 4 - Average total and incremental Poisson's ratios versus longitudinal strain for monotonically loaded Specimen $19-1 / M / 29 / 0.6$

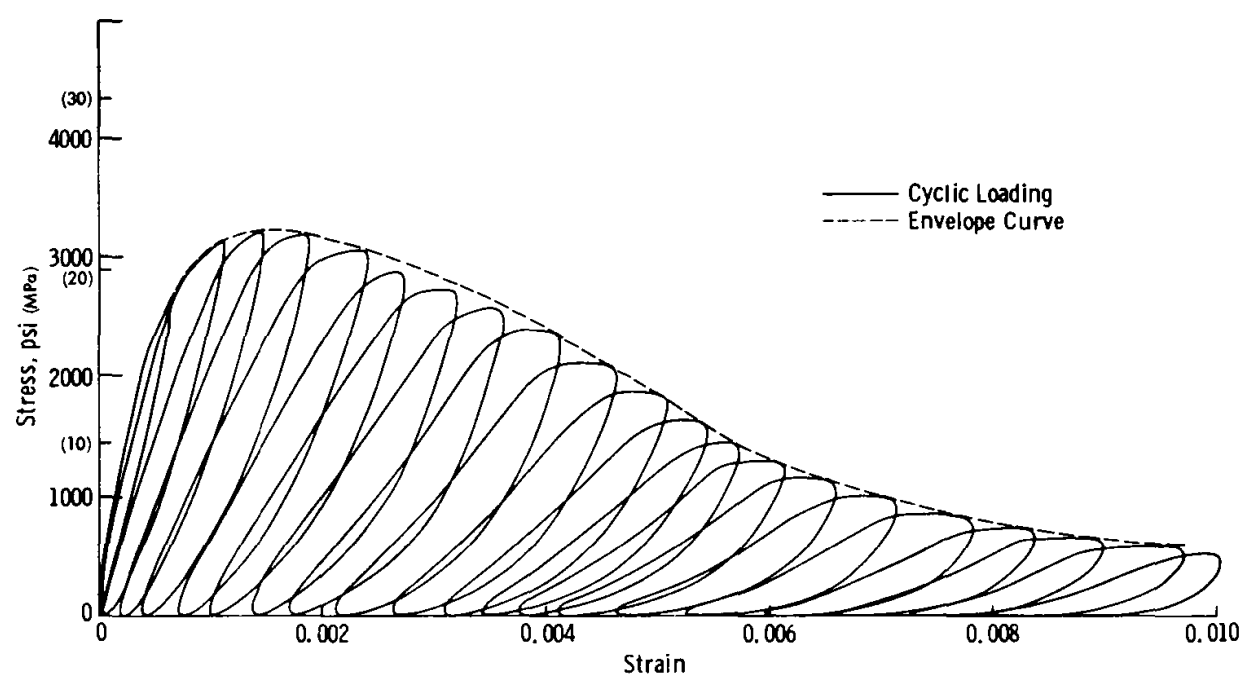

Fig. 5 - Mortar under cyclic loading. Cycles to the envelope, Test Specimen 3$3 / C E N / 28 / 0.6$ 
generally exhibit more cracking and finer cracks than the monotonic specimens. For cycling at large strains, deformation consists mainly of sliding along these macroscopic cracks. The resistance to deformation is provided primarily by friction. With each cycle, the friction increases as the load increases, resulting in a stress-strain curve that is concave upward. Eventually, strains are attained at which the cracks are extended and additional damage occurs, and the curve becomes concave downward.
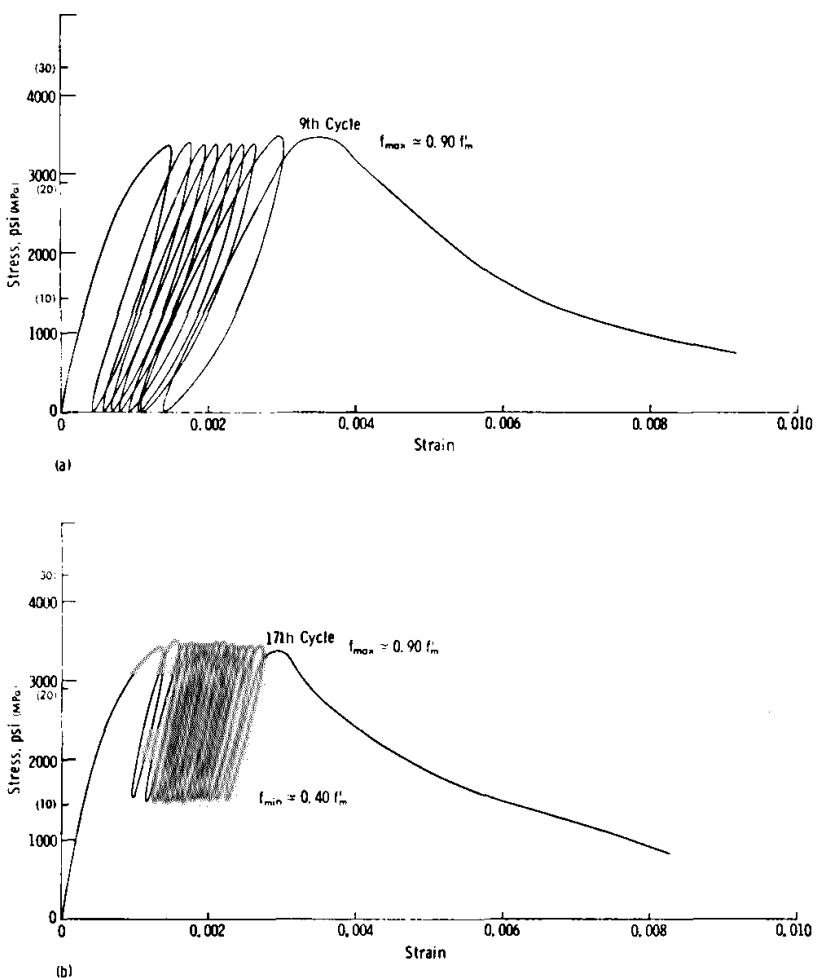

Fig. 6 - Effect of minimum stress on the number of cycles to failure for the same maximum stress, Test Specimens $41-1 / S L / 15 / 0.6$ and $41-2 / S L / 15 / 0.6$
For cyclic loading between fixed stresses (Fig. 6), the strain increment first decreases and then increases. The closer the peak of the current cycle is to the envelope curve, the greater is the increase in strain. For a particular maximum stress, the greater the stress range, the more rapid the degradation. In Fig. 6, the specimen with a zero minimum stress failed on the ninth cycle, while the specimen with a minimum stress equal to 40 percent of the compressive strength failed on the 17th cycle. This agrees with the observations of Karsan and Jirsa ${ }^{11}$ and Awad and Hilsdor ${ }^{13}$ for concrete.

For cyclic loading to specified strains (Fig. 7), the stress drop and residual strain accumulation decrease with each cycle, suggesting the possibility of ultimate stability. However, in the current study, the stress drop and residual strain accumulation did not stabilize through a maximum of 42 cycles.

For cycles to the common points (Fig. 8), in a procedure used by Karsan and Jirsa" to establish a stability limit for concrete, the rate of degradation decreased rapidly. After just 5 to 10 cycles the curves converged, and it became increasingly difficult to locate the next common point. These results seem to suggest that mortar has a stability limit. However, since the material was subjected to a decreasing stress and strain with each cycle, stabilization of the curves may not indicate the existence of a stability limit for the material (i.e., a stress below which no additional damage is done).

\section{ANALYSIS OF TEST RESULTS Uniqueness of the envelope curve}

Sinha, Gerstle, and Tulin; ${ }^{14}$ Karsan and Jirsa;" and Spooner, Pomeroy, and Dougill ${ }^{4}$ feel that the envelope curve is unique for concrete. However, in another investigation studying the cyclic behavior of concrete, Awad and Hilsdorf ${ }^{13}$ demostrate that while the ascending branch of the stress-strain curve is essentially independent of the load regime, the descending branch depends on the loading procedure. Loading regimes

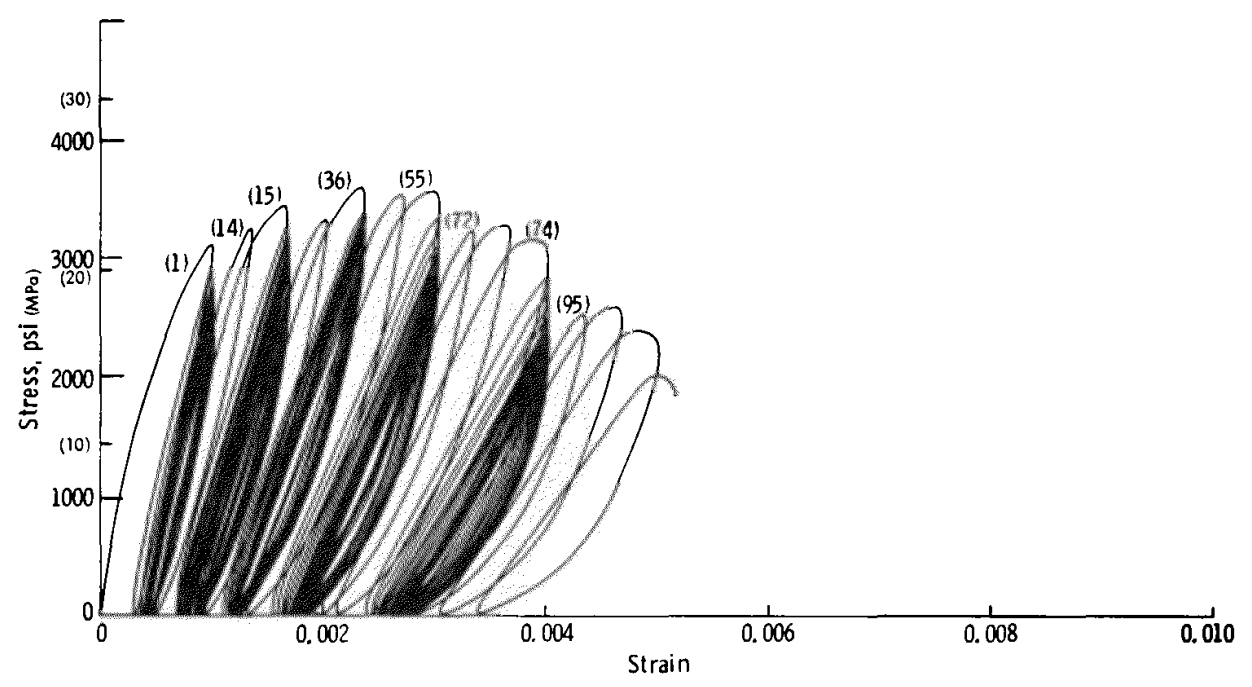

Fig. 7 - Cycles to specified strains, Test Specimen 25-2/CMS/14/0.6 


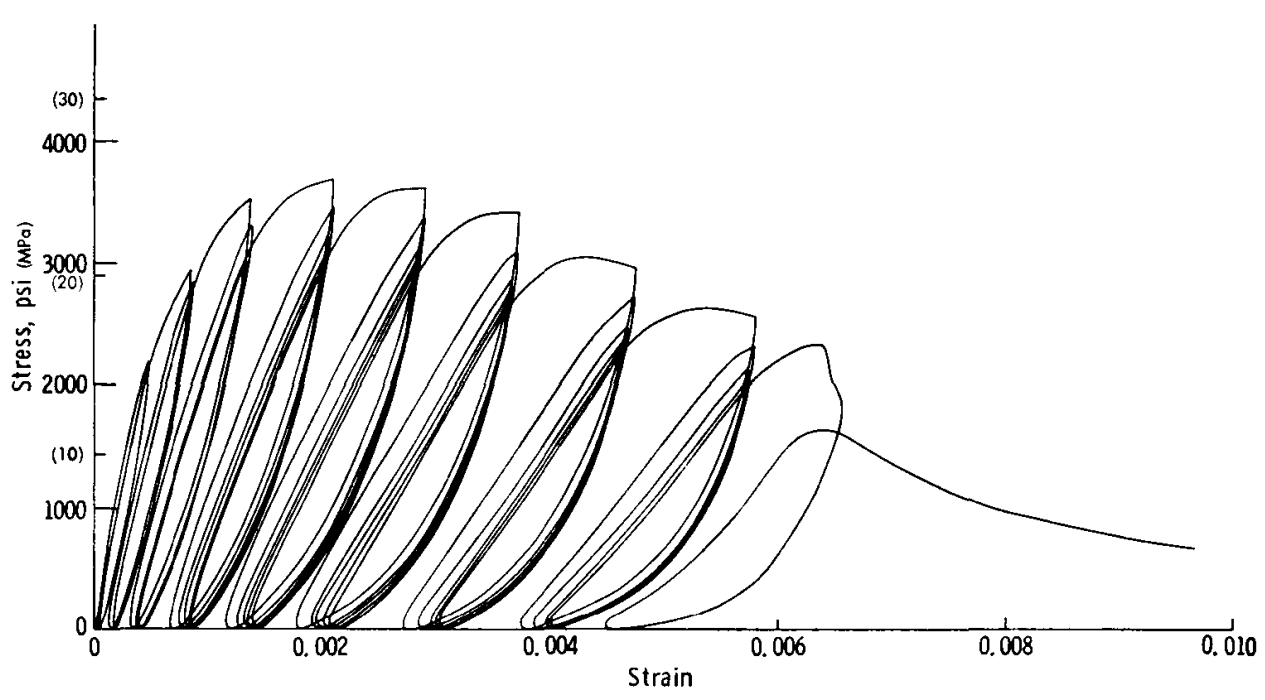

Fig. 8 - Cycles to common points, Test Specimen $14-3 / C P / 28 / 0.6$

which extend the amount of time during which a specimen is under load result in a higher descending branch of the stress-strain curve. An analysis of the current tests on the mortar constituent of concrete corroborates this finding. While the shape of the ascending branch of the envelope is essentially the same for all types of loading, the descending branch is flatter and higher for cyclic loading than it is for monotonic loading. A comparison of companion cyclic and monotonic specimens (Table 2) demonstrates, in the overwhelming number of cases, that the cyclic envelope is higher at a strain equal to twice the strain at the peak stress. The non-uniqueness of the envelope curves is likely due to creep caused by the greater time of loading and the greater distribution of macroscopic cracks in the cyclic specimens.*

\section{Residual strain}

In the current series of tests, residual strain was measured for initial load cycles with peak strains as low as 0.00027 (Table 3 ). This value is lower than the value of 0.0004 obtained for concrete by Spooner. ${ }^{2}$ The corresponding stress in the current tests was 29 percent of the mortar compressive strength $\left(0.29 f_{m}^{\prime}\right)$ which is approximately equal to the stress in concrete at which Hsu et al. ${ }^{\text {is }}$ first observed an increase in bond cracking due to the application of a compressive load. In the current situation, however, no "bond cracking" occurred due to the absence of coarse aggregate. Clearly the nonlinear response of mortar is due to something other than what is traditionally referred to as microcracking.

The rate of accumulation of residual strain was studied for a number of load regimes. The relationship between the residual strain and the maximum strain per cycle appears to be largely independent of the loading procedure for cycles that reach the envelope (Fig. 9). However, the relationship is dependent on the load regime if a cycle fails to reach the envelope. This point is amply illustrated in Fig. 10 and 11 for cycles with a constant strain increment and cycles between fixed stresses.

For cycles that reach the envelope, the accumulation of the residual strain $\varepsilon_{r}$ is very low for small applied (unloading) strains $\varepsilon_{u}$ (Fig. 9). The rate of residual strain accumulation increases with increasing applied strain, and at large strains the curves become linear with a slope of 1 . At this stage, an increase in the maximum strain causes approximately the same increase in the residual strain. This occurs when the material is on the descending branch of the stress-strain curve and seems to indicate that the major contributor to residual strain is sliding along the cracks. The apparent uniqueness of the residual strain curve for cycles to the envelope is worthy of further study.

For cycles with a constant strain increment, the cycles typically fall below the envelope in the middle portion of the descending branch of the curve. As shown in Fig. 10, the residual versus maximum strain $\left(\varepsilon_{r}-\varepsilon_{u}\right)$ curves initially have the same shape as those for cycles to the envelope. But at about twice the strain at the peak of the envelope, the slope of the curve exceeds 1 , indicating that the increase in residual strain is larger than the applied strain increment. The point at which the slope of these curves exceeds 1 approximately coincides with the point at which the peak stress drops below the envelope. As the loading strain increases further, the slope of the curve becomes less than 1 .

For cycles between fixed stresses, the maximum strain per cycle represents the envelope strain only on the first and final cycles, and the $\varepsilon_{r}-\varepsilon_{u}$ curves for these tests are approximately straight lines. As shown in Fig. 11 , the $\varepsilon_{r}-\varepsilon_{u}$ lines bridge the residual strain versus maximum strain curves obtained for cycles to the envelope. The lower the maximum stress for a cycle, the greater is the residual strain for a given value of maximum strain.

* As a note of moderation, it must be stated that while the envelope curve clearly depends on the loading regime, the envelope curve may still be considered to be unique in many practical cases. In fact, this assumption was made in Reference 10 to develop an analytical representation for the test results reported in this paper. 


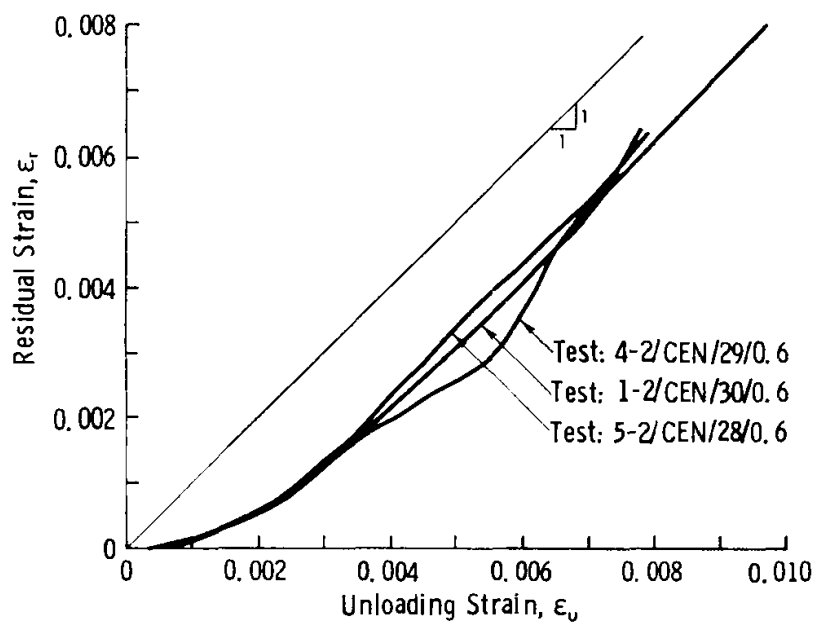

Fig. $9-$ Residual strain $\varepsilon_{\mathrm{r}}$ versus unloading strain $\varepsilon_{\mathrm{u}}$ for cycles to the envelope

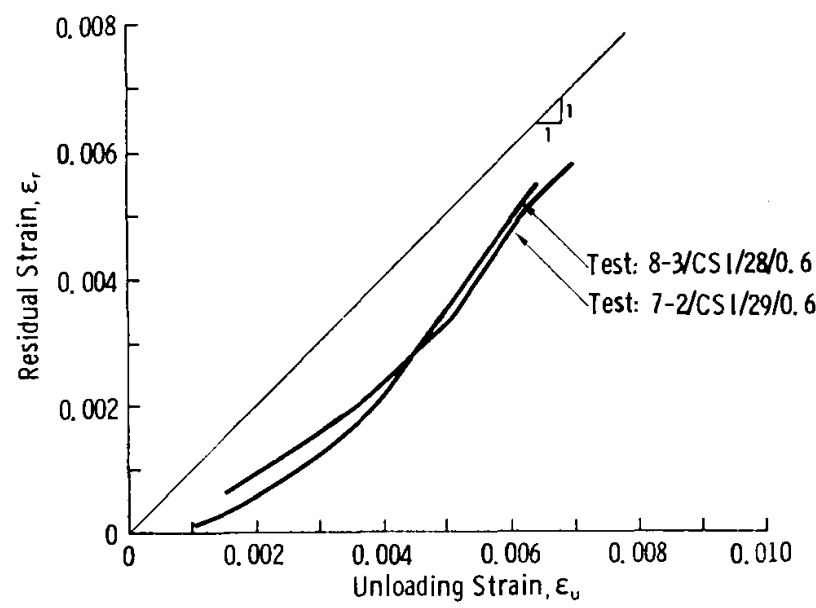

Fig. $10-$ Residual strain $\varepsilon_{\text {, }}$ versus unloading strain $\varepsilon_{\mathrm{u}}$ for cycles with a constant strain-increment

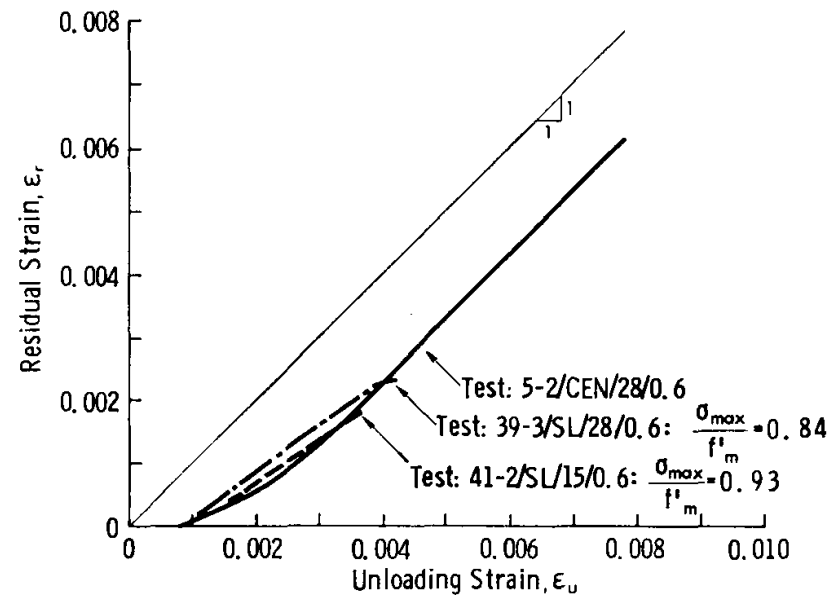

Fig. $11-\varepsilon_{1}-\varepsilon_{u}$ lines for cycles between fixed stresses bridging $\varepsilon_{r}-\varepsilon_{u}$ curve for cycles to the envelope

Table 2 - Comparison of monotonic and cyclic loading regimes

\begin{tabular}{l|c|c|c|c}
\hline \multicolumn{1}{c|}{$\begin{array}{c}\text { Test } \\
\text { specimen* }\end{array}$} & $\begin{array}{c}\text { Peak } \\
\text { stress } \\
f_{m}^{\prime} \\
\text { psi }\end{array}$ & $\begin{array}{c}\text { Strain } \\
\text { corres- } \\
\text { ponding } \\
\text { to } f_{m}^{\prime} \\
\varepsilon_{m}\end{array}$ & $\begin{array}{c}\text { Approx. } \\
\text { time to } \\
\text { reach a } \\
\text { strain of } \\
0.004, \\
\text { min }\end{array}$ & $\begin{array}{c}\text { Stress } \\
\text { at } \\
\varepsilon_{m} \\
\text { psi }\end{array}$ \\
\hline $1-1 / \mathrm{M} / 30 / 0.6$ & 4800 & 0.0023 & 15 & 2100 \\
$1-2 / \mathrm{CEN} / 30 / 0.6$ & 5100 & 0.0025 & 20 & 3000 \\
\hline $3-1 / \mathrm{M} / 28 / 0.6$ & 3800 & 0.0016 & 15 & 1800 \\
$3-2 / \mathrm{M} / 28 / 0.6$ & 3600 & 0.0020 & 15 & 2200 \\
$3-3 / \mathrm{CEN} / 28 / 0.6$ & 3200 & - & 85 & 2500 \\
\hline $5-1 / \mathrm{M} / 28 / 0.6$ & 4000 & 0.0019 & 15 & 2500 \\
$5-2 / \mathrm{CEN} / 28 / 0.6$ & 4200 & - & 70 & 3800 \\
$5-3 / \mathrm{SL} / 29 / 0.6$ & - & - & 120 & 3300 \\
\hline $6-1 / \mathrm{M} / 28 / 0.6$ & 4000 & 0.0019 & 15 & 2000 \\
$6-2 / \mathrm{CP} / 28 / 0.6$ & 4100 & - & 100 & 3800 \\
\hline $8-1 / \mathrm{M} / 29 / 0.6$ & 4200 & 0.0024 & 15 & 2600 \\
$8-2 / \mathrm{CP} / 29 / 0.6$ & 4200 & - & 100 & 2200 \\
$8-3 / \mathrm{CS} 1 / 28 / 0.6$ & 4000 & - & 70 & 1600 \\
\hline $9-1 / \mathrm{M} / 28 / 0.6$ & 3900 & 0.0021 & 15 & 1100 \\
$9-2 / \mathrm{CP} / 29 / 0.6$ & 4200 & - & 100 & 3600 \\
$9-3 / \mathrm{CS} 1 / 29 / 0.6$ & 4200 & - & 120 & 3400 \\
\hline $11-1 / \mathrm{M} / 28 / 0.6$ & 3600 & 0.0021 & 15 & 2400 \\
$11-3 / \mathrm{SL} / 28 / 0.6$ & - & - & 240 & 2900 \\
\hline $25-1 / \mathrm{M} / 14 / 0.6$ & 3900 & 0.0023 & 15 & 1900 \\
$25-2 / \mathrm{CMS} / 14 / 0.6$ & 3600 & - & 215 & 2500 \\
\hline $26-1 / \mathrm{M} / 14 / 0.6$ & 3800 & 0.0019 & 15 & 1500 \\
$26-2 / \mathrm{CMS} / 14 / 0.6$ & 3700 & - & 240 & 3100 \\
\hline $38-1 / \mathrm{M} / 29 / 0.5$ & 5300 & 0.0020 & 30 & 1300 \\
$38-2 / \mathrm{CMS} / 30 / 0.5$ & 5300 & - & 550 & 4400 \\
\hline
\end{tabular}

* See Apendix

$1 \mathrm{psi}=6.9 \mathrm{kPa}$.

Table 3 - Residual strain $\varepsilon_{r}$ and initial modulus of elasticity $E_{j}$ for first cycle

\begin{tabular}{|c|c|c|c|c|c|c|}
\hline \multirow[b]{2}{*}{$\begin{array}{c}\text { Test } \\
\text { specimen }\end{array}$} & \multirow[b]{2}{*}{$\begin{array}{l}f_{m}^{\prime}, \\
\text { psi }\end{array}$} & \multirow{2}{*}{$\begin{array}{c}\text { Maximum } \\
\text { stress for } \\
\text { first cycle } \\
\div f_{m}^{\prime}\end{array}$} & \multirow{2}{*}{$\begin{array}{l}\text { Maximum } \\
\text { strain for } \\
\text { first cycle }\end{array}$} & \multicolumn{2}{|c|}{$E_{i} \times 10^{-6}, \mathrm{psi}$} & \multirow[b]{2}{*}{$\begin{array}{l}\text { Residual } \\
\text { strain } \varepsilon_{r}\end{array}$} \\
\hline & & & & $\begin{array}{l}\text { Virgin } \\
\text { curve }\end{array}$ & $\begin{array}{c}\text { Upon } \\
\text { reloading }\end{array}$ & \\
\hline $1-2 / \mathrm{CEN} / 30 / 0.6$ & 5100 & 0.41 & 0.00043 & 5.3 & 5.9 & 0.00007 \\
\hline $7-2 / \mathrm{CS} 1 / 29 / 0.6$ & 3800 & 0.54 & 0.00050 & 3.9 & 4.8 & 0.00017 \\
\hline $7.3 / \mathrm{CSl} / 28 / 0.6$ & 3800 & 0.56 & 0.00050 & 4.2 & 4.5 & 0.00007 \\
\hline $9-3 / \mathrm{CS} 1 / 29 / 0.6$ & 4200 & 0.39 & 0.00050 & 4.8 & 4.9 & 0.00008 \\
\hline $20-3 / \mathrm{CSI} / 29 / 0.6$ & 3800 & 0.52 & 0.00050 & 4.0 & 4.8 & 0.00012 \\
\hline $36-3 / \mathrm{CSI} / 29 / 0.5$ & 5600 & 0.29 & 0.00027 & 3.6 & 4.2 & 0.00003 \\
\hline $37-2 / \mathrm{CSI} / 28 / 0.5$ & 4800 & 0.40 & 0.00033 & 5.0 & 5.6 & 0.00005 \\
\hline
\end{tabular}

*See Appendix.

$1 \mathrm{psi}=6.9 \mathrm{kPa}$. 


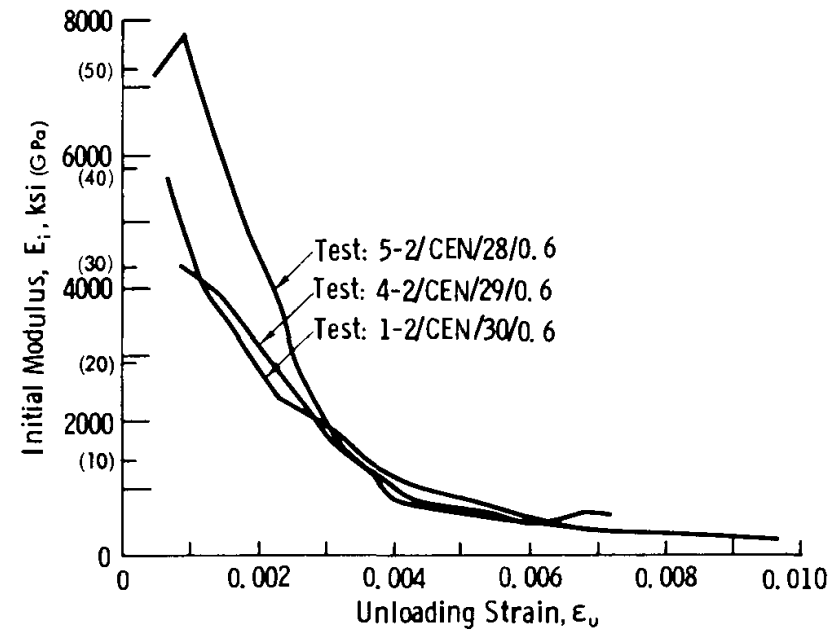

Fig. 12 - Initial modulus of elasticity $\mathrm{E}_{\text {, versus un- }}$ loading strain $\varepsilon_{\mathrm{u}}$ for cycles to the envelope

\section{Initial modulus of elasticity}

As demonstrated by Spooner et al., ,3,4 the initial modulus of elasticity is a sensitive measure of damage and structural change in cement paste and concrete. For the current tests on mortar, the initial modulus of elasticity $E_{i}$ is taken as the secant modulus for the stress range 625-1250 psi (4.3-8.6 $\mathrm{MPa})$. This range was selected for ease in measurement.

$E_{i}-\varepsilon_{u}$ curves are shown in Fig. 12 for cycles to the envelope. For the first unloading from the envelope at maximum strains as large as 0.0005 and at stresses as high as $0.56 f_{m}^{\prime}$, the initial modulus increases at the beginning of the next cycle (Table 3 ). This indicates that for the first cycle a certain amount of compaction or consolidation occurs within the specimen. This consolidation not only results in the accumulation of residual strain, but increases the stiffness of the material. This first loading utilizes a portion of the available strain capacity, but does not seem to weaken the structure of the material. For additional cycles, the initial modulus may increase somewhat more (Fig. 12) and then begins to decrease.

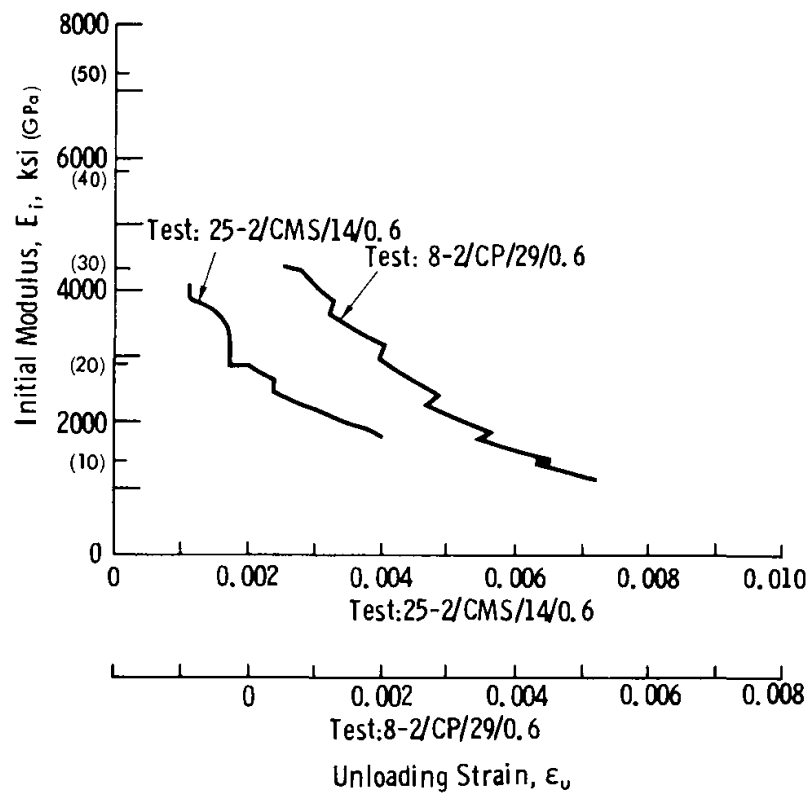

Fig. 13 - Initial modulus of elasticity $\mathrm{E}_{\mathrm{i}}$ versus unloading strain $\varepsilon_{\mathrm{u}}$ for cycles to specified strains and cycles to common points

Fig. 13 shows $E_{i}$ versus $\varepsilon_{u}$ for two loading regimes, one with cycles to specified strains and one with cycles to common points. The plots show that the initial modulus decreases for additional cycles to the same maximum strain and even for cycles to successively lower strains at the common points, indicating that damage in mortar is a function of more than just the maximum strain. Table 4 shows that $E_{i}$ will continue to decrease for a number of cycles to the same strain. However, the results in Table 4 illustrate that in a significant number of cases $E_{i}$ stabilizes, although residual strain accumulation and stress drop continue.

\section{Stability limit}

Fig. 14 shows the log-log plot of the stress at the peak of each cycle versus the number of cycles to the same strain for three specimens with cycles to specified

Table 4 - Changes in initial modulus of elasticity $E_{i}$ and stress $\sigma$ for cycles to specified strains

\begin{tabular}{|c|c|c|c|c|c|c|c|c|c|c|}
\hline \multirow[t]{2}{*}{$\begin{array}{c}\text { Test } \\
\text { specimen }^{*} \\
\end{array}$} & \multirow[t]{2}{*}{$\begin{array}{l}f_{m i}^{\prime} \\
\text { psi }\end{array}$} & \multirow[t]{2}{*}{$\begin{array}{c}\text { Maximum } \\
\text { strain }\end{array}$} & \multicolumn{5}{|c|}{$\begin{array}{l}\text { Initial modulus } E^{j} \\
\text { for Cycle } j, \times 10^{-6}, \text { psi }\end{array}$} & \multicolumn{2}{|c|}{$\begin{array}{l}\text { Stress } o^{j} \text { for } \\
\text { Cycle } j, \text { psi }\end{array}$} & \multirow[t]{2}{*}{$\begin{array}{l}\text { No. of } \\
\text { cycles, } \ell\end{array}$} \\
\hline & & & $E_{i}^{\prime}$ & $E_{i}^{2}$ & $E_{t}^{3}$ & $E_{i}^{4}$ & $E_{i}^{\ell}$ & $\sigma^{\prime}$ & $\sigma^{\prime}$ & \\
\hline \multirow[t]{5}{*}{$25-2 / \mathrm{CMS} / 14 / 0.6$} & 3600 & 0.0010 & 4.5 & 4.5 & 4.5 & - & 3.8 & 3130 & 2420 & 13 \\
\hline & & 0.0017 & 3.5 & 3.2 & 3.2 & - & 3.2 & 3480 & 2600 & 20 \\
\hline & & 0.0023 & 2.74 & 2.74 & - & 一 & 2.74 & 3610 & 2900 & 18 \\
\hline & & 0.0030 & 2.25 & 2.13 & 2.13 & 一 & 2.08 & 3590 & 2710 & 15 \\
\hline & & 0.0040 & 1.92 & 1.74 & 1.65 & 1.6 & 1.6 & 3100 & 2110 & 21 \\
\hline \multirow[t]{5}{*}{$26-2 / \mathrm{CMS} / 14 / 0.6$} & 3700 & 0.0009 & 4.16 & 4.16 & 4.0 & - & 3.48 & 2880 & 2480 & 15 \\
\hline & & 0.0016 & 3.2 & 3.1 & - & - & 2.73 & 3580 & 2830 & 20 \\
\hline & & 0.0024 & 2.4 & 2.4 & 2.3 & 2.3 & 2.13 & 3630 & 2540 & 42 \\
\hline & & 0.0044 & 1.5 & 1.5 & 1.5 & 1.4 & 1.4 & 3060 & 2130 & 22 \\
\hline & & 0.0053 & 1.3 & 1.3 & 1.3 & 1.3 & 1.3 & 24,70 & 1520 & 28 \\
\hline \multirow[t]{3}{*}{$38-2 / \mathrm{CMS} / 30 / 0.5$} & 5300 & 0.0024 & 4.3 & 3.9 & 3.7 & 3.7 & 3.7 & 5140 & 3930 & 21 \\
\hline & & 0.0031 & 3.4 & 3.4 & 3.2 & 3.1 & 3.1 & 4960 & 3890 & 21 \\
\hline & & 0.0037 & 2.9 & 2.8 & 2.7 & 2.7 & 2.6 & 4660 & 3500 & 17 \\
\hline \multirow[t]{2}{*}{$38-3 / \mathrm{CMS} / 29 / 0.5$} & 5300 & 0.0014 & 6.1 & 6.1 & 6.0 & - & 5.9 & 4500 & 3500 & 25 \\
\hline & & 0.0021 & 5.5 & 5.5 & 5.5 & 5.5 & 5.5 & 4800 & 3790 & 35 \\
\hline
\end{tabular}

$\ell=$ last cycle to maximum strain

* See Appendix.

$1 \mathrm{psi}=6.9 \mathrm{kPa}$. 


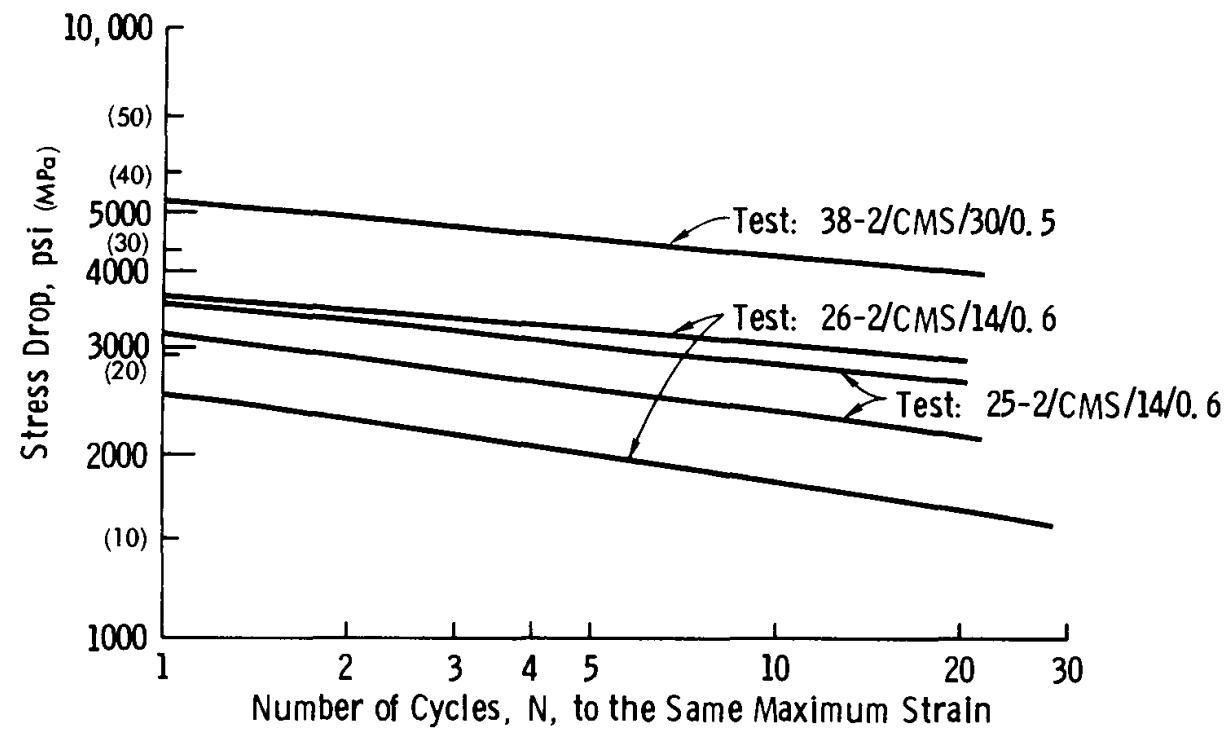

Fig. 14 - Stress drop versus number of cycles for cycles to specified strains

strains. The figure shows that the rate of stress drop decreases as the cycling continues. However, the straight lines indicate that the stress drop does not stabilize. It is also observed that the lines are roughly parallel, independent of the maximum strain, watercement ratio, and age. These results would seem to indicate that a stability limit does not exist for the mortar constituent of concrete. However, the apparent stabilization in the initial modulus of elasticity observed in Table 4 suggests that the level of damage has stabilized. These results point to a stability limit in terms of damage, but not in terms of overall structural change (i.e., creep). They also suggest that two mechanisms are acting, one resulting in damage and one resulting in time-dependent deformation, and that these two mechanisms do not necessarily act in concert.

\section{DISCUSSION}

Spooner et al. ${ }^{2}$ feel that the maximum strain is the most important factor controlling the degradation of concrete and cement paste. The results of the current investigation indicate that the range of strain (loading strain plus unloading strain) and/or the number of cycles of load are also important. For cyclic loading with a constant strain increment, the $\varepsilon_{r}-\varepsilon_{u}$ curve achieves a slope greater than 1 in the descending branch of the envelope (Fig. 10), indicating that the increase in residual strain exceeds the increase in maximum strain. If the maximum strain was the only factor of importance, the increase in residual strain would, at most, be equal to the increase in maximum strain. For cyclic loading between fixed stress limits, the residual strain $\varepsilon$, corresponding to a given value of maximum strain $\varepsilon_{u}$ is larger than the value that would be obtained if the cycling were carried to the envelope (Fig. 11), indicating that a greater number of cycles and/or an increase in strain range affect the structure of the material.

One of the strongest arguments suggesting that loading cycles play an important role in the degradation of mortar is illustrated in Fig. 13 and Table 4: the modulus of elasticity continues to drop for specimens subjected to either a constant maximum strain or a decreasing maximum strain with each cycle of load. While the maximum strain is dominant, subsequent cycles clearly result in significant additional damage to the material.

A comparison of the test results with tests on cement paste and concrete illustrates many points of similarity. All three materials become nonlinear at low strains. ${ }^{2,3}$ The peak stress and the corresponding strain of mortar and concrete increase with increasing age and decreasing water-cement ratio. ${ }^{4,8,16}$ The stress-strain envelopes for mortar and concrete yield a steeper descending branch with increasing strength. ${ }^{4} 16$ The descending branch of the envelope for both mortar and concrete is flatter and higher for cyclic loading than for monotonic loading. ${ }^{13}$ With increasing cycles of load, the initial modulus of elasticity for mortar decreases, as does the initial modulus of cement paste and concrete..$^{2,3}$ The degradation of mortar and concrete is faster, the higher the maximum stress and the lower the minimum stress for cycles between fixed stresses. ${ }^{11,13}$

These many similarities in behavior suggest that not only are the factors affecting damage quite similar in cement paste, mortar, and concrete, but the nonlinear behavior of mortar (and likely paste) dominates the behavior of concrete. If this conclusion is correct, cracking and damage mechanisms other than bond and mortar microcracking play the dominant roles in controlling the primary stress-strain behavior of concrete prior to failure. It seems clear that the structural changes in paste and mortar deserve considerably more attention than they have received to date.

\section{CONCLUSIONS}

The following conclusions are drawn from the analysis of the tests of the mortar constitutent of concrete under uniaxial compression: 
1. The behavior of concrete and mortar is highly similar, indicating that the mortar constitutent may control the primary stress-strain behavior of concrete.

2. Initial loading to low strains increases the modulus of elasticity, indicating compaction of the material occurs at low strains without significant damage.

3. The early accumulation of residual strain and the change in the initial modulus of elasticity indicate that the nonlinear behavior is attributable to factors other than bond microcracking.

4. The damage process in mortar is continuous under monotonic load as indicated by the continuous increase in Poisson's ratio.

5. Mortar appears to have a stability limit in terms of damage, but not in terms of strain accumulation.

6. The maximum strain appears to be the major factor in controlling damage in mortar, but the number of load cycles and/or the total strain range play significant roles.

7. In the strictest sense, the envelope curve is not independent of the load regime.

\section{ACKNOWLEDGMENTS}

The research presented in this paper was supported by the $\mathrm{Na}$ tional Science Foundation under NSF Grants ENG76-09444 and CME79-18414. Additional support was provided by University of Kansas General Research Allocation \#2408-XO-0038.

\section{REFERENCES}

1. Spooner, D. C., "The Stress-Strain Relationship for Hardened Cement Pastes in Compression," Magazine of Concrete Research (London), V. 24, No. 79, June 1972, pp. 85-92.

2. Spooner, D. C., and Dougill, J. W., "A Quantitative Assessment of Damage Sustained in Concrete During Compressive Loading," Magazine of Concrete Research (London), v. 27, No. 92, Sept. 1975, pp. 151-160.

3. Spooner, D. C.; Pomeroy, C. D.; and Dougill, J. W., "Damage and Energy Dissipation in Cement Pastes in Compression," Magazine of Concrete Research (London), V. 28, No. 94, Mar. 1976, pp. 21-29.

4. Spooner, D. C.; Pomeroy, C. D.; and Dougill, J. W., "The Deformation and Progressive Fracture of Concrete," Joint Meeting, Mechanical Properties of Ceramics (2), British Ceramic Society and Institute of Physics (London, Dec. 1974), Proceedings, British Ceramic Society, London, No. 25, May 1975, pp. 101-107.

5. Maher, A., and Darwin, D., "A Finite Element Model to Study the Microscopic Behavior of Plain Concrete," CRINC Report No. SL-76-02, University of Kansas Center for Research, Lawrence, Nov. 1976, $83 \mathrm{pp}$.

6. Maher, A., and Darwin, D., "Microscopic Finite Element Model of Concrete," Proceedings, First International Conference on Mathematical Modeling (St. Louis, Aug.-Sept. 1977), University of Missouri-Rolla, 1977, v. 3, pp. 1705-1714.
7. Shah, Surendra P., and Winter, George G., "Inelastic Behavior and Fracture of Concrete," ACI Journal, Proceedings V. 63, No. 9, Sept. 1966, pp. 925-930.

8. Cook, D. J., and Chindaprasirt, P., "Influence of Loading History Upon the Compressive Properties of Concrete," Magazine of Concrete Research (London), V. 32, No. 111, June 1980, pp. 89100.

9. $\mathrm{ACl}$ Committee 224, "Control of Cracking in Concrete Structures," (ACI 224R-80), Concrete International: Design \& Construction, V. 2, No. 10, Oct. 1980, pp. 35-76.

10. Maher, A., and Darwin, D., "Mortar Constituent of Concrete Under Cyclic Compression,"' SM Report No, 5, Structural Engineering and Engineering Materials, University of Kansas Center for Research, Lawrence, Oct. 1980, 165 pp.

11. Karsan, I. Demir, and Jirsa, James O., "Behavior of Concrete Under Compressive Loadings," Proceedings, ASCE, V. 95, ST12, Dec. 1969, pp. 2543-2563.

12. Rüsch, Hubert, "Researches Toward a General Flexural Theory for Structural Concrete," ACI Journal, Proceedings V. 57, No. 1, July 1960 , pp. 1-28.

13. Awad, M. E., and Hilsdorf, H. K., "Strength and Deformation Characteristics of Plain Concrete Subjected to High Repeated and Sustained Loads," Abeles Symposium on Fatigue of Concrete, SP-41, American Concrete Institute, Detroit, 1974, pp. 113.

14. Sinha, B. P.; Gerstle, Kurt H.; and Tulin, Leonard G., "Stress-Strain Relations for Concrete Under Cyclic Loading," $\mathrm{ACl}$ Journal, Proceedings V. 61, No. 2, Feb. 1964, pp. 195-212.

15. Hsu, Thomas T. C.; Slate, Floyd O.; Sturman, Gerald M.; and Winter, George, "Microcracking of Plain Concrete and the Shape of the Stress-Strain Curve," ACI Journal, Proceedings V. 60, No. 2, Feb. 1963, pp. 209-224.

16. Carrasquillo, Ramon L.; Nilson, Arthur H.; and Slate, Floyd O., "Properties of High Strength Concrete Subject to Short-Term Loads," ACI Journal, Procedings V. 78, No. 3, May-June 1981, pp. 171-178.

\section{APPENDIX KEY TO SPECIMEN IDENTIFICATION}

The specimens are identified as follows: Identification: $\mathrm{i}-\mathrm{j} / \mathrm{XXX} / \mathrm{N} / \mathrm{R}$

$$
\text { in which } \begin{aligned}
\mathrm{i} & =\text { batch number } \\
\mathrm{j} & =\text { specimen number, in Batch } \mathrm{i} \\
\mathrm{XXX} & =\text { type of load regime } \\
\mathrm{N} & =\text { age in days } \\
\mathrm{R} & =\text { water-cement ratio }
\end{aligned}
$$

Types of load regimes - XXX

$$
\begin{aligned}
\mathrm{M} & =\text { monotonic loading } \\
\mathrm{CEN} & =\text { cycles to the envelope } \\
\mathrm{CSI} & =\text { cycles with constant strain increment } \\
\mathrm{SL} & =\text { cycles between fixed stresses } \\
\mathrm{CMS}= & \text { cycles to specified (constant maximum) } \\
& \text { strains } \\
\mathrm{CP} & =\text { cycles to common points }
\end{aligned}
$$

Example: $6-2 / \mathrm{M} / 28 / 0.6$

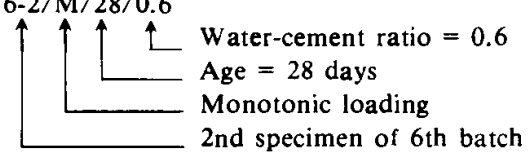

